\section{Design for a Simulated Nursery for Water Runoff Research}

\author{
Janet C. Cole ${ }^{1}$, Vicki L. Stamback ${ }^{2}$, and Charlie Gray ${ }^{3}$ \\ Department of Horticulture and Landscape Architecture, Oklahoma State \\ University, Stillwater, OK 74078
}

Additional index words. irrigation methods, water contamination, water management

Abstract. Few data are available to indicate the chemical concentration of runoff from nursery operations, and, to our knowledge, no model systems have been developed to gain such data. This paper describes such a model system, in which nursery production beds have been designed to collect and quantify runoff water and contaminant concentrations so that management practices may be identified to decrease potential pollution problems.

Increasing public concern for environmental issues has necessitated evaluating plant nursery production practices that may affect the environment. The nursery industry releases large quantities of water that potentially may contaminate groundwater and surface water. Runoff from production areas may contain nitrate, $\mathrm{P}$, and other elements commonly applied as fertilizer, as well as various pesticides.

Currently, there are no rigid guidelines in most areas for chemical content of water released from nurseries. The regulation of runoff is, however, becoming more widespread as the U.S. Environmental Protection Agency sets standards for maximum allowable concentrations of various chemicals in runoff from nurseries, greenhouses, and other agricultural enterprises (Environmental Protection Agency, 1992). Enforcement of these standards would affect nursery producers, since few current data indicate the types and quantities of chemicals that are released in runoff. Some states have begun to monitor water runoff from selected container nurseries to define potential contamination and production practices that may be altered to reduce contamination.

Although chemical losses during field production have been studied (Hergert, 1986; Mancino and Troll, 1990; Schuman et al., 1973), few studies involve container systems (Dumroese et al., 1991; Stewart et al., 1981). Container-plant production systems are unique in that the plants are grown in an artificial medium that contains little, if any, soil, restricts the root volume, and limits the water and fertilizer reservoir. Models developed for evaluating runoff from field production are inadequate for predicting runoff from container systems. New systems, therefore, must

Received for publication 13 Nov. 1992. Accepted for publication 31 Mar. 1993. Oklahoma Agricultural Experiment Station journal series no. 6087. We thank William Cole for the schematic accompanying this paper. The cost of publishing this paper was defrayed in part by the payment of page charges. Under postal regulations, this paper therefore must be hereby marked advertisement solely to indicate this fact. be developed for determining the concentration of contaminants in container plant runoff. We present a design that simulates a nursery in which plants would be produced using standard practices, but all runoff would be collected and analyzed for chemical concentration. This system can be used for collecting runoff from nursery production plots so that laboratory procedures can be performed to measure water quality.

Two study areas, one with sprinkler irrigation and the other with drip irrigation, were constructed so that several compartments could be used for various fertilization practices or plant species (Fig. 1). Each bed was $9.1 \mathrm{~m}$ wide and $30 \mathrm{~m}$ long. The entire surface was covered with a mat consisting of a polyethylene membrane bonded to a polypropylene fabric (Geoseal; Phillips Fibers, Greenville, S.C.). This membrane was chosen over more commonly available polyethylene mats because it was more resistant to wear. Each bed was divided into four quadrants, each of which contained six sections. These sections were framed with aged railroad ties. The sides of the ties were covered with $15-\mu \mathrm{m}$ black polyethylene bonded to the mat with contact cement to prevent water movement between the sections.

The irrigation systems were controlled by an eight-station time clock (Rainbird RCM-8; Rainbird, Glendora, Calif.) that regulated solenoid valves (Greenlawn, Denver) on each quadrant. The water source for both beds was a $3.8-\mathrm{cm}$ feeder line attached to a $15-\mathrm{cm}$ pres-
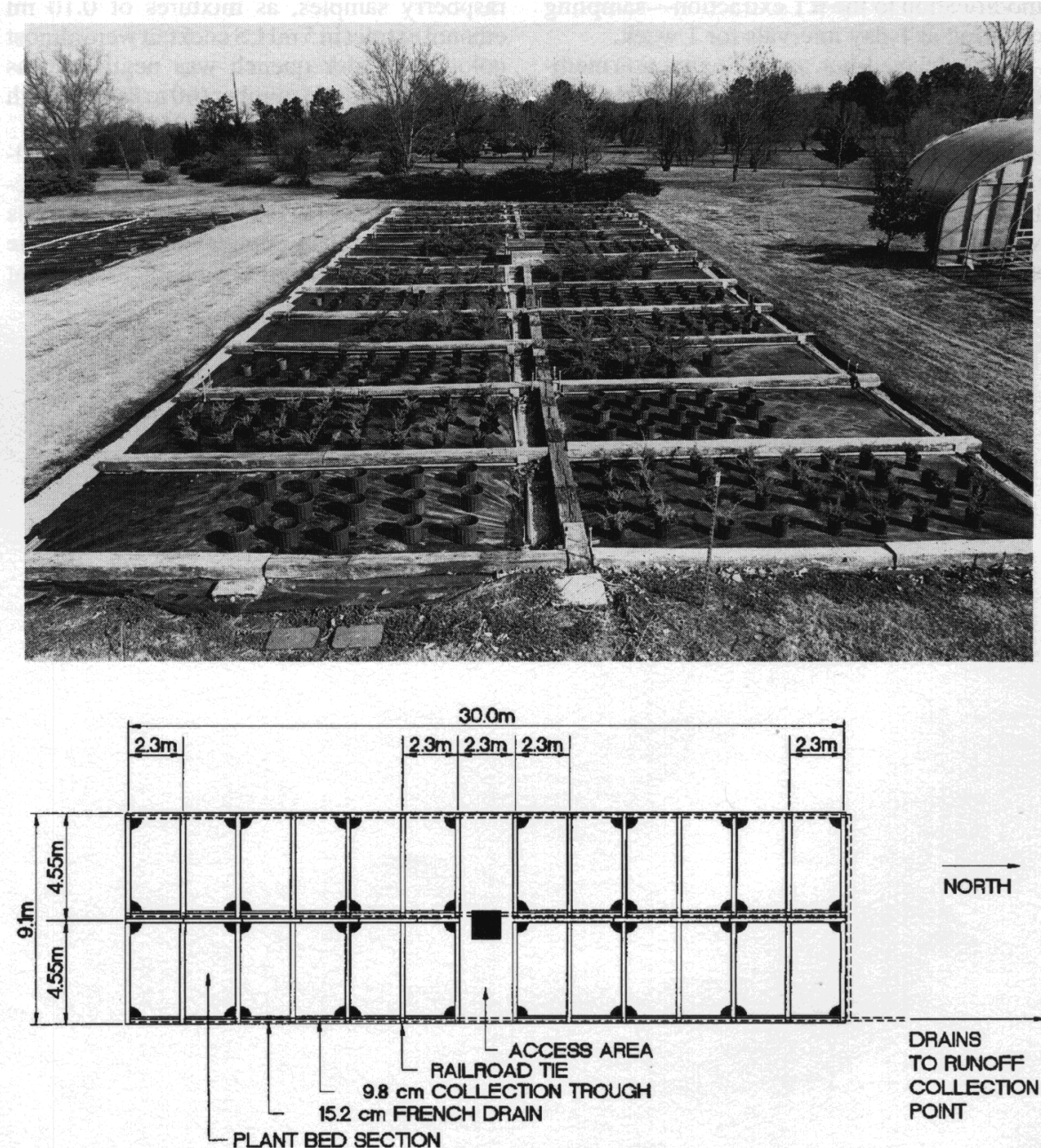

Fig. 1. Installation devoted to research on the quality of runoff produced during nursery plant production. (top) View from the south end. (bottom) Schematics of layout. All dimensions are to the center of the railroad ties. = sprinkler head, $\mathbf{D}=$ injection control box. 
surized potable water line. The north half of each bed (northeast and northwest quadrants) was plumbed with an injector (Dosmatic Plus, J-F Equipment Co., Lewisville, Texas) to supply fertilizer.

On the sprinkler bed, a group of four sprinklers (Rainbird 15Q, Rainbird) irrigated two adjacent sections with a total area of $21.2 \mathrm{~m}^{2}$. The sprinkler heads were installed at the outer comers of each pair of section compartments (Fig. 1, bottom). The spray pattern of each head covered one-fourth of a circle with $\approx 4.5$ $\mathrm{m}$ radius.

Drip irrigation was applied with drip rings (Dramm, Manitowoc, Wis.) appropriate for the size of pots on the bed. Each ring was connected with a $1.5-\mathrm{mm}$-i.d., 122-cm-long tube to a $1.9-\mathrm{cm}$-diameter flexible polyethylene supply line laid along the railroad ties on either side of each section. Half of the pots in each section were irrigated from the polyethylene supply line on the north, and the other half received water from the south line. All 1.9-cm-diameter polyethylene supply lines were connected to a 2.5 -cm-diameter polyvinyl chloride (PVC) central line in the middle of the bed, and 1.5 -cm-diameter polyethylene connector line on the outside of the bed to form a loop on each quadrant. Pressure on the drip bed is controlled by pressure regulators $(0.14$ $\mathrm{MPa}$; Senninger Irrigation, Orlando, Fla.) installed for each quadrant, and in-line drains (16A-FDV, Rainbird) that released excess water from the lines when the water turned off.

Water application to each bed was monitored by a flow meter (Great Plains Indus- tries, Wichita, Kan.) installed in the $3.8 \mathrm{~cm}$ source line for each bed. Runoff was collected in troughs constructed of 10-cm-diameter PVC pipe cut in half lengthwise and installed across the lowest edge of each section. The sprinkler bed had a $2 \%$ slope to the east and the drip bed a $2 \%$ slope to the west; thus, troughs were on the east side of each section on the sprinkler bed and west side of each section on the drip bed. A 1.9-cm-diameter hole was drilled in each trough and plugged with a rubber stopper for water collection. The stopper could be removed for rapid drainage of water from the collection troughs. Drainage flowed into a 15.2-cm-diameter french drain, then was carried to an area north of the production beds where it could be collected.

Both beds were calibrated periodically by placing twenty $20.3-\mathrm{cm}$-diameter $\times 3.8-\mathrm{cm}$ deep (1.2 liters) saucers, evenly spaced, within each section. Water was collected for a predetermined time, measured, and recorded. This process was repeated four times, then analysis of variance was used to determine uniformity within and between sections. Distribution patterns were readily analyzed and adjusted. The maximum difference in output between the sections under sprinklers was $0.28 \mathrm{~mm} \cdot \mathrm{min}^{-1}$, and under drip it was $0.18 \pm 0.03 \mathrm{ml} \cdot \mathrm{min}^{-1}$.

Both beds were irrigated before $0600 \mathrm{HR}$ daily to avoid fluctuations in water pressure that occurred during later hours and to avoid windeffects on sprinkler patterns. A ram gauge and recording thermometer installed near the beds monitored environmental conditions.

Data generated from studies on the beds might include total water released and concentrations of nitrates, $\mathrm{P}$, and pesticides in that runoff. These data can be taken throughout a growing season on various experimental units. This system establishes a method for obtaining the information needed to identify practices that may reduce runoff contamination while maintaining plant growth and quality. Further construction details for these beds can be obtained from J.C.C.

\section{Literature Cited}

Dumroese, R.K., D.S. Page-Dumroese, and D.L. Wenny. 199 1. Managing pesticide and fertilizer leaching and runoff in a container nursery, $\mathrm{p}$. 27-33. In: Proc. Intermountain Forest Nursery Assn., U.S. Dept. Agriculture, Forest Service Gen. Tech. Rpt. RM-211.

Environmental Protection Agency. 1992. National pollutant discharge elimination system, request for comment on alternative approaches for phase II storm water program. 40 CFR Part 122. Federal Register 57(175):41,344-41,356.

Hergert, G.W. 1986. Nitrate leaching through sandy soil as-affected by sprinkler irrigation management. J. Environ. Quality 15:272-277.

Mancino, C.F. and J. Troll. 1990. Nitrate and ammonium leaching losses from $\mathrm{N}$ fertilizers applied to 'Penncross' creeping bentgrass. HortScience 25:194-196.

Schuman, G.E., R.E. Burwell, R.F. Piest, and R.G. Spomer. 1973. Nitrogen losses in surface runoff from agricultural watersheds on Missouri Valley loess. J. Environ. Quality 2:299-302.

Stewart, J.A., L.J. Lund, and R.L. Branson. 1981. Nitrogen balances for container-grown privet. J. Amer. Soc. Hort. Sci. 106:565-569. 